\title{
The influence of the growth cavity on damage of welded steel
}

\author{
El-Ahmar Kadi ${ }^{1} \cdot$ Benguediab Mohamed $^{1}$
}

Received: 12 April 2015 / Accepted: 19 June 2015 / Published online: 20 February 2016

(C) Springer-Verlag London 2016. This article is published with open access at Springerlink.com

\begin{abstract}
The aim of our work is the modeling of damage in the welded metal using the finite element method and the concepts of fracture mechanics based on local approaches. The use of Gurson-Tvergaard-Needleman (GTN) model has enabled us to model the behavior of damage of welded steel, which is described as being due to the growth of cavities.
\end{abstract}

Keywords Growth of cavities · Volume deformation . Damage $\cdot$ GTN $\cdot$ Weld $\cdot$ Steel

\section{Introduction}

In the past three decades, simulation of ductile damage behaviors in metallic materials had known a large deformation in the development of several continuous models, the evolution of damage in the stress triaxiality is the key to each these studies. Today, ductile fracture is governed by three physical mechanisms: initially, nucleation of inexistent cavities, after, growth of these cavities in an appropriate loading, and finally, the coalescence of adjacent cavities. The study of this failure mechanism involves the use of local approaches that are based on knowledge of the field of stress and strain.

McClintock's work and those of Rice and Tracey, based on the growth of cavities, is an undeniable contribution to the development of fracture mechanics. These approaches considered that the rate of growth of the cavities is modeled by an exponential function based on the rate triaxiality constraints $\tau$,

El-Ahmar Kadi

elahmar.kadi@gmail.com

1 University of Djillali Liabes, Sidi Bel Abbes, Algeria defined by the ratio $\sigma_{\mathrm{m}} / \sigma_{\text {eq }}$. From this work, several models have been proposed, in particular, based on continuous damage models (coupled models) as the model of Gurson.

Gurson has developed a constitutive model for porous ductile media, based on a rigid-plastic material behavior, and the upper bound theorem of plasticity, based on detailed phenomenological studies of the behavior of materials containing periodic distributions of cylindrical and spherical voids.

Our goal is to provide a methodology possibly including finite element modeling to describe the various pathways for study options and choose the most appropriate approach to the description of failure mechanisms of welded steel. We will perform a mechanical characterization to identify the major physical phenomena to be considered in modeling. On this basis, we propose the approach of a constitutive and a damage criterion specific to welded steel.

\section{Presentation of the Gurson-Tvergaard-Needleman (GTN) model}

The experimental results indicate the central role of the growth of cavities in ductile metals [1-3]. All these studies have focused on metallic materials and showed that the cavities formed on the second phase particles, or by decohesion between a particle and the matrix, or the rupture of a particle. The final rupture occurs after the growth phase of adjacent cavities until their final coalescence. Analysis growth of cavities in infinite plastic material shows that this growth is highly dependent on the hydrostatic stress $[4,5]$. And the coalescence of the cavities is generated by a high rate of triaxiality. This prediction was confirmed by a series of specimens tested on more severely notched least in the case of steel $[6,7]$.

Given the experimental results, there has been a growing interest in the use of the growth and coalescence of cavities to 
describe ductile metals. Many examples of research focused on the growth of a single cavity in an infinite elasto-plastic solid, for different stress states $[4,5,8]$. Based on analyzes equivalent to a spherical cavity, Gurson developed a model to describe the behavior of a ductile porous solid $[9,10]$. In this model, the parameter $f$, volume fraction of porosity, is the only parameter of material damage and the response is very sensitive to its evolution. This model was extended by Needleman and Rice to account for the germination of cavities [11], and then by Tvergaard and Needleman to reflect the coalescence of cavities [12, 13]. Gurson-Tvergaard-Needleman (GTN) model is based on the micromechanical model developed by Gurson [9]. It allows describing the growth of a spherical cavity in a rigid perfectly plastic matrix leading to the expression of the plasticity criterion given by (1):

$\Phi=\frac{\sigma_{\mathrm{eq}}{ }^{2}}{\sigma_{\mathrm{y}}{ }^{2}}+2 f^{*} \cdot q_{1} \cdot \cosh \left(\frac{3}{2} q_{2} \frac{\sigma_{\mathrm{m}}}{\sigma_{\mathrm{y}}}\right)-\left(1+q_{3}\left(f^{*}\right)^{2}\right)=0$

With the constitutive parameters $q_{1}, q_{2}, q_{3}\left(q_{3}=\left(q_{1}\right)^{2}\right)$.

$f^{*}$ represents the modified volumetric void fraction which is the function of $f$ defined by:

$f^{*}= \begin{cases}f & \text { for } f \leq f_{\mathrm{c}} \\ f_{\mathrm{c}}+\delta\left(f-f_{\mathrm{c}}\right) & \text { for } f>f_{\mathrm{c}}\end{cases}$

with

$\delta=\frac{f_{\mathrm{u}}^{*}-f_{\mathrm{c}}}{f_{\mathrm{F}}-f_{\mathrm{c}}}$

Where $f_{\mathrm{u}}^{*}$ is the ultimate value of $f^{*}=1 / q_{1}, f_{\mathrm{F}}$ the volume fraction of void in the final rupture and $f_{\mathrm{c}}$ the critical volume fraction of void.

The volume fraction of void $f$ is divided into a new term nucleation cavities $f_{\text {nucleation }}$ and a second term $f_{\text {growth }}$ corresponding to the growth of existing cavities. The change of the volume fraction of cavities is given by the following expression:

$d f=d f_{\text {nucleation }}+d f_{\text {growth }}$

with

$d f_{\text {growth }}=(1-f) d \varepsilon_{\mathrm{kk}}^{\mathrm{p}}$

and

$d f_{\text {nucleation }}=a d \varepsilon_{\mathrm{eq}}^{\mathrm{p}}$

where $\varepsilon_{\mathrm{kk}}^{\mathrm{p}}$ the total of normal component of the plastic deformation, $\varepsilon_{\mathrm{eq}}^{\mathrm{p}}$ the equivalent plastic strain. The parameter of germination «a», which is selected in the event that the void nucleation follows a normal distribution, depends on the equivalent plastic strain.

To calculate a cracked structure using the GTN model, several parameters are required:
- Generally, the constitutive parameters are fixed at $q_{1}=1.5$, $q_{2}=1$ et $q_{3}=\left(q_{1}\right)^{2}$. In a recent study, Perrin and Leblond [14] have demonstrated the existence of a correlation between the parameter $q_{1}$ and porosity $f$ and for a porosity tends to zero $q_{1}$ takes the value about 1.47. Under a wide bibliographic study on the model parameters of GTN, it was shown that the parameter $q_{1}$ takes values between 1.1 and 1.5 [15].

- $f_{0}$, initial porosity, is a parameter related to the material (measured from microscopic observations or estimated from the formula of Franklin).

- $\delta$ which represents the slope acceleration of the growth of porosity and «a» parameter of the continuous germination may be arbitrarily set or adjustable parameters considered.

- $f_{\mathrm{c}}$, which corresponds to the onset of coalescence, is an adjustable parameter using numerical simulation.

\section{Law of behavior}

To determine the behavior law of welded steel, we used an experimental test geometry corresponds to ASTM D638 M1A, Fig. 1. The test was made on Instron tensile machine, the mechanical properties of welded steel for a speed of $0.001 \mathrm{~s}^{-1}$ and at room temperature $23^{\circ} \mathrm{C}$ are given as follows:

BM (base metal):

$\mathrm{E}=183 \mathrm{GPa}$ and $\sigma_{\mathrm{e}}=300 \mathrm{MPa}$ and $v=0.3$.

WM (weld metal):

$\mathrm{E}=180 \mathrm{GPa}$ and $\sigma_{\mathrm{e}}=400 \mathrm{MPa}$ and $v=0.3$.

HAZ (heat affected zone):

$\mathrm{E}=450 \mathrm{GPa}$ and $\sigma_{\mathrm{e}}=205 \mathrm{MPa}$ and $v=0.3$.

Working on axisymmetric notched specimens (AE), it is possible to study the multiaxial stresses, only using a tensile test. These samples are used to study conditions of plane strain and plane stress.

For a notched specimen, as the elastic limit is not exceeded, the maximum stress is in the bottom of the notch by the phenomenon of stress concentration. The elastic limit is reached first at this point. If the test continues to be deformed plastically, deformed zone extends and eventually invade the entire notched section. The load then reaches the limit load of the specimen; it is greater than it would be without fault (notched). Consider for that first a cylinder of material in the notch portion of the specimen, if it were isolated, lengthen it along its 
Fig. 1 A48 steel curve (BM, WM, and HAZ). (full colored version available online)

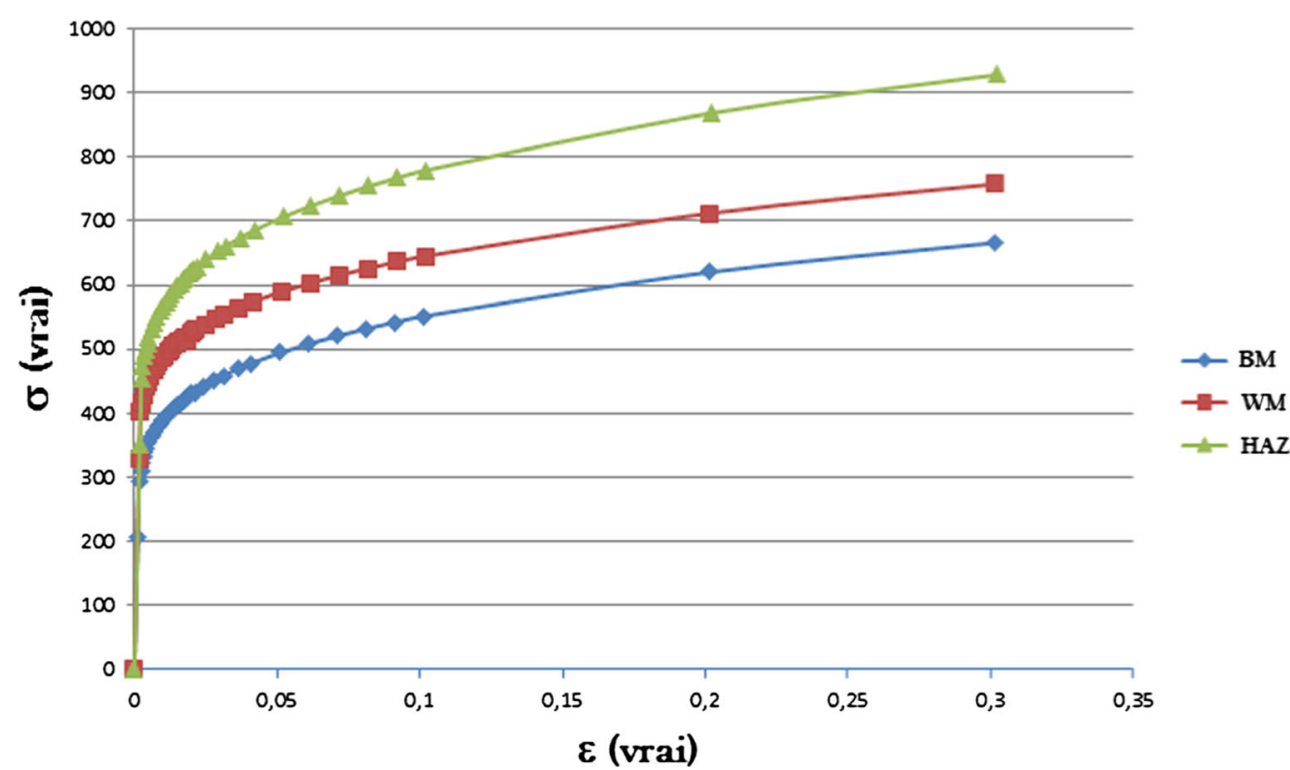

axis and along its diameter would shrink in order to maintain a constant volume. Included in the notch between the two parties unnotched remaining elastic and deform slightly, it can only contract in the same way and it appears radial stress of tension. To satisfy the yield criterion (von Mises or Tresca), it is necessary to increase all the axial stress. Thus, the plastic deformation confined raises the general level of stress and stress triaxiality rate $\beta$. This is defined by the Eq. (5):

$\beta=\frac{\sigma_{\mathrm{m}}}{\sigma_{\mathrm{eq}}}$

$\sigma_{\mathrm{m}}:$ Mean stress defined as

$\sigma_{\mathrm{m}}=\left(\frac{1}{3}\left(\sigma_{11}+\sigma_{22}+\sigma_{33}\right)\right)$

$\sigma_{\text {eq }}$ : Von Mises equivalent stress.

For a cylindrical specimen having a groove notch root radius $(R)$ leaving a collar radius $(a)$ in the minimum section, the calculation of stress distributions and deformations is complicated and cannot be completely solved analytically. Simplifying assumptions are necessary such as equality between radial and tangential distortions in the minimum section when $Z=0$. It follows that the radial and tangential stresses are equal and that deflector is independent of the radial coordinate $(r)$ in this section. With these assumptions, the equations of equilibrium and the plasticity criterion, it is shown that:

$\frac{d \sigma_{r r}}{d_{r}}=-\frac{\sigma_{e q}}{\rho}$

With $r$ the radius of curvature of the lines isostatic, where they intercept the plane $Z=0$. Bridgman [16] assumed that the isostatic lines can be treated as circles that intersect at right angles the surface of the ring is cut. [17] The radius of curvature $(\rho)$ is given by the relation (7).

The integration of the differential Eq. (6) leads to Eq. (8):

$\rho=\frac{a^{2}+2 a R-r^{2} 2 r}{2 r}$

The average axial stress $\bar{\sigma}_{-z z}$ that is to say the load on the specimen is given by the expression (9):

And $\left\{\begin{array}{c}\sigma_{r r}=\sigma_{\theta \theta}=\sigma_{e q} \ln \left(1+\frac{a^{2}-r^{2}}{2 a R}\right) \\ \sigma_{Z Z}=\sigma_{e q}\left[1+\ln \left(1+\frac{a^{2}-r^{2}}{2 a R}\right)\right]\end{array}\right.$

$\bar{\sigma}_{-z z}=\sigma_{e q}\left(1+\frac{2 R}{a}\right) \ln \left(1+\frac{a}{2 R}\right)$

The rate of stress triaxiality is maximum on the axis of the specimen such that:

$\frac{\sigma_{\mathrm{m}}}{\sigma_{\mathrm{eq}}}=\frac{1}{3}+\ln \left(1+\frac{a}{2 R}\right)$

\section{Choice of geometry}

We chose to work with AE notched axisymmetric specimens at four different radii of curvature in order to study the influence of the rate of stress triaxiality on the behavior of the material "damage". The four radii studied are $R=80 \mathrm{~mm}$ (AE80), $10 \mathrm{~mm}$ (AE10), $4 \mathrm{~mm}$ (AE4), and 
$2 \mathrm{~mm}$ (AE2). For each radius, we make the same test for three different zones (BM, WM, and HAZ) to see the influence of stress triaxiality. We consider the simplest analysis traction monotonous. Given the imperfections of the model, we clear despite all the benefits of its components dependent plasticity criterion. Tensile tests on the specimens were carried out in AE imposed displacement. Geometry axisymmetric notched specimens (AE) Hourglass type (Fig. 2) such that the total length is $46 \mathrm{~mm}$, the width of the shaft is $10 \mathrm{~mm}$, and the notch root is $5 \mathrm{~mm}$. The height of the scored area will vary with the radius of curvature $(R=80,10,4$, and $2 \mathrm{~mm})$.

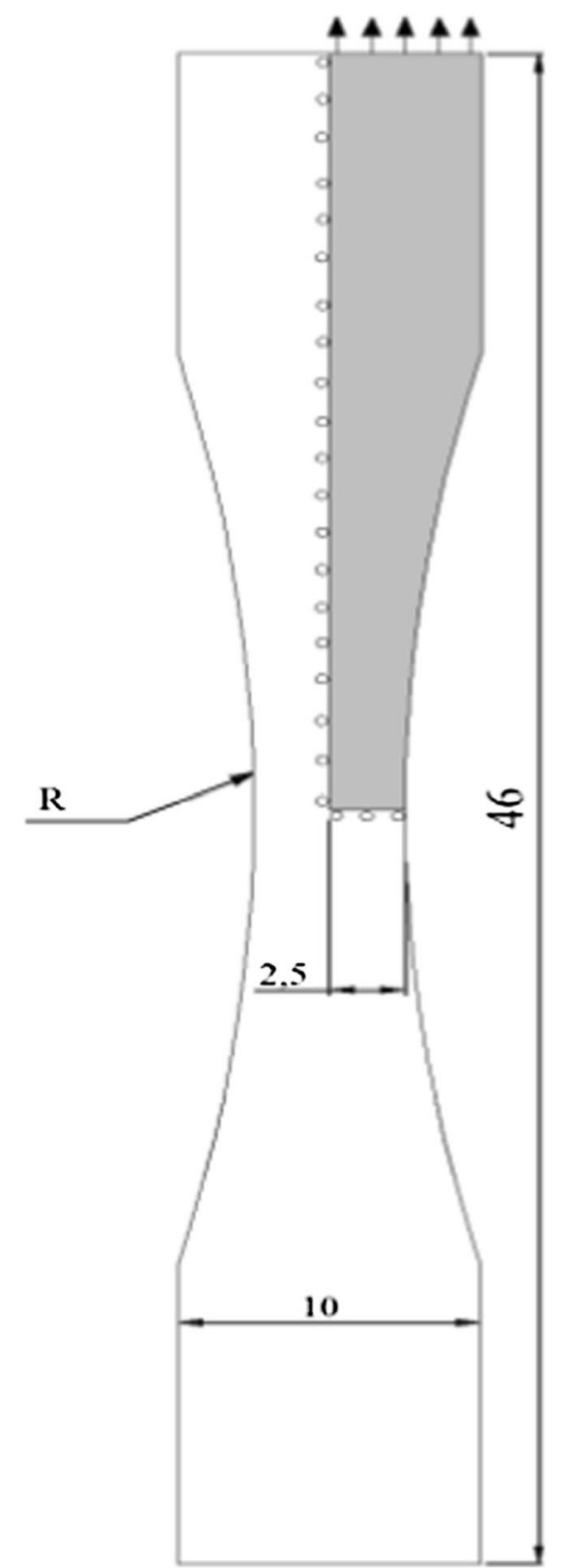

Fig. 2 Notched specimen type hourglass with a radius of curvature $\mathrm{R}(\mathrm{mm})$

\section{Mesh}

Notched geometries were studied by symmetry (axisymmetric), only half of the specimen is meshed with axisymmetric element quadratic reduced integration (called cax4r). Thus, by symmetry, it is possible to mesh the half length to represent the entire structure. In the notched zone, the mesh is finite, contrary to the smooth zone where it is coarser. The total number of node varies depending on the geometry studied: 905 nodes and 280 elements for the AE80, 1080 nodes and 345 elements for the AE10, 1273 nodes and 400 elements for AE4, and 1527 nodes and 400 elements for the AE2. Figure 3 shows the mesh sizes used in the region of the notch and the entire half length.

\section{Results and discussion}

The finite element method has allowed us to numerically analyze and determine the distribution of strain fields adjacent of the notch. These results are obtained from analysis tests on four specimens tensile triaxiality different $\beta=0.33,0.44,0.6$, and 0.8 , and from three different zone (BM, WM, and HAZ).

Figure 4 presents the evolution and the longitudinal strain localization in useful zones.

We note firstly that the deformations are concentrated in bottom of notch, the concentration decreases as one moves away from it; secondly, this concentration increases with increasing radius curvature, same things for different zone.

Figure 5 shows the variation of the equivalent stress of Von Mises function of time produced by the finite element and measured in the center of the specimen (the

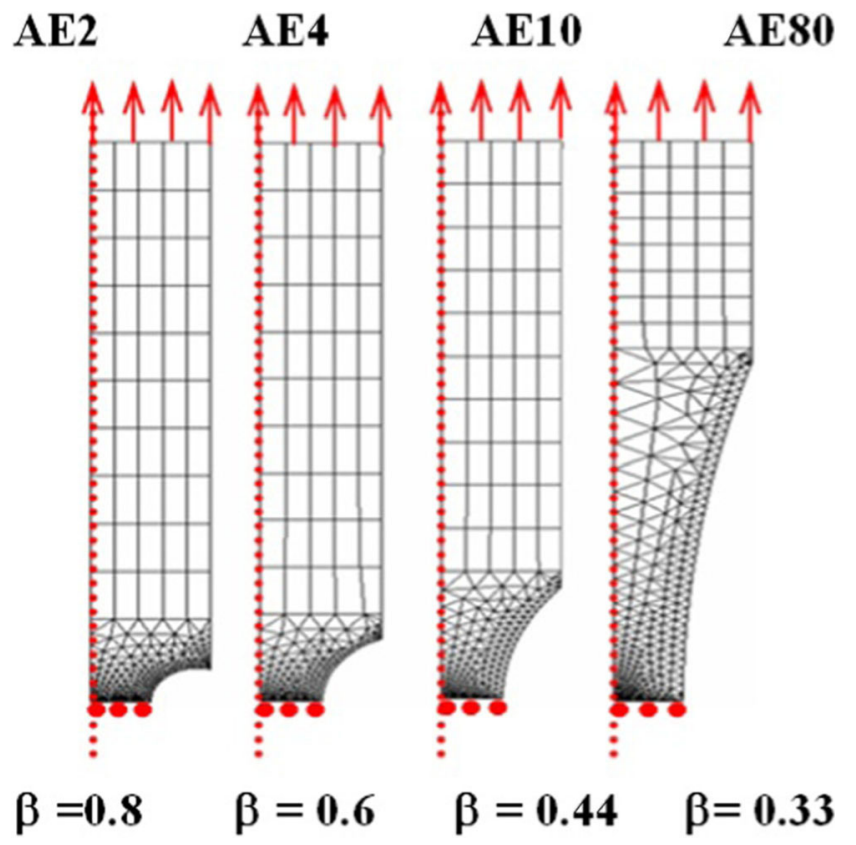

Fig. 3 Mesh specimens AE. (full colored version available online) 

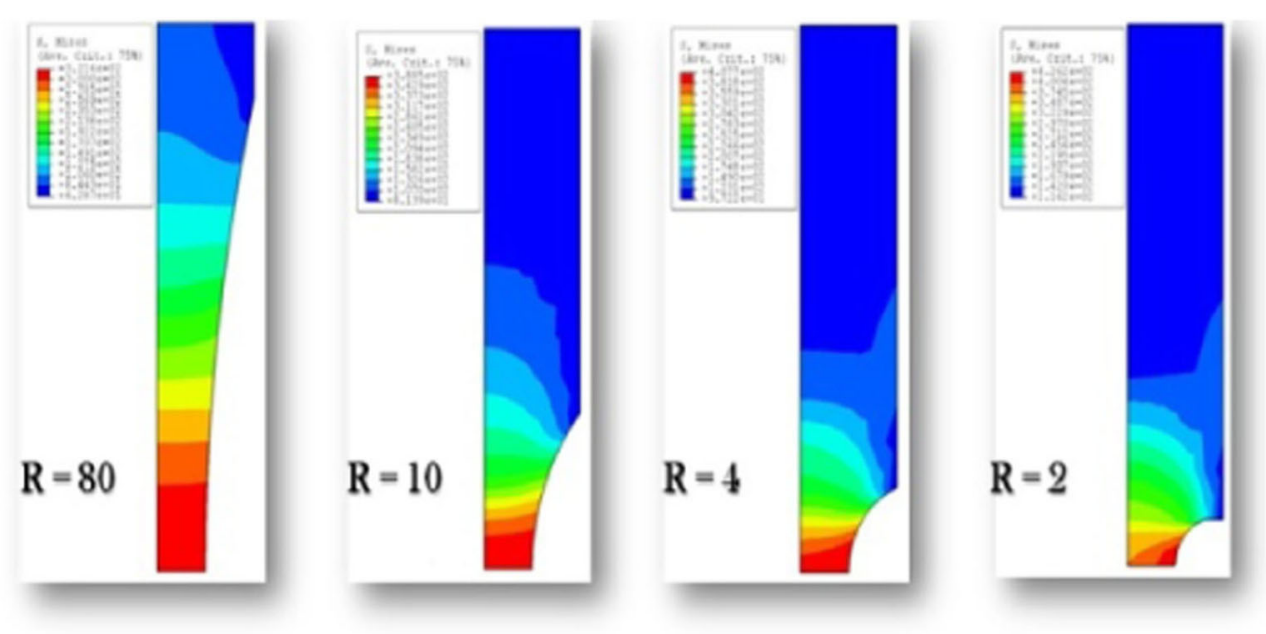

BM
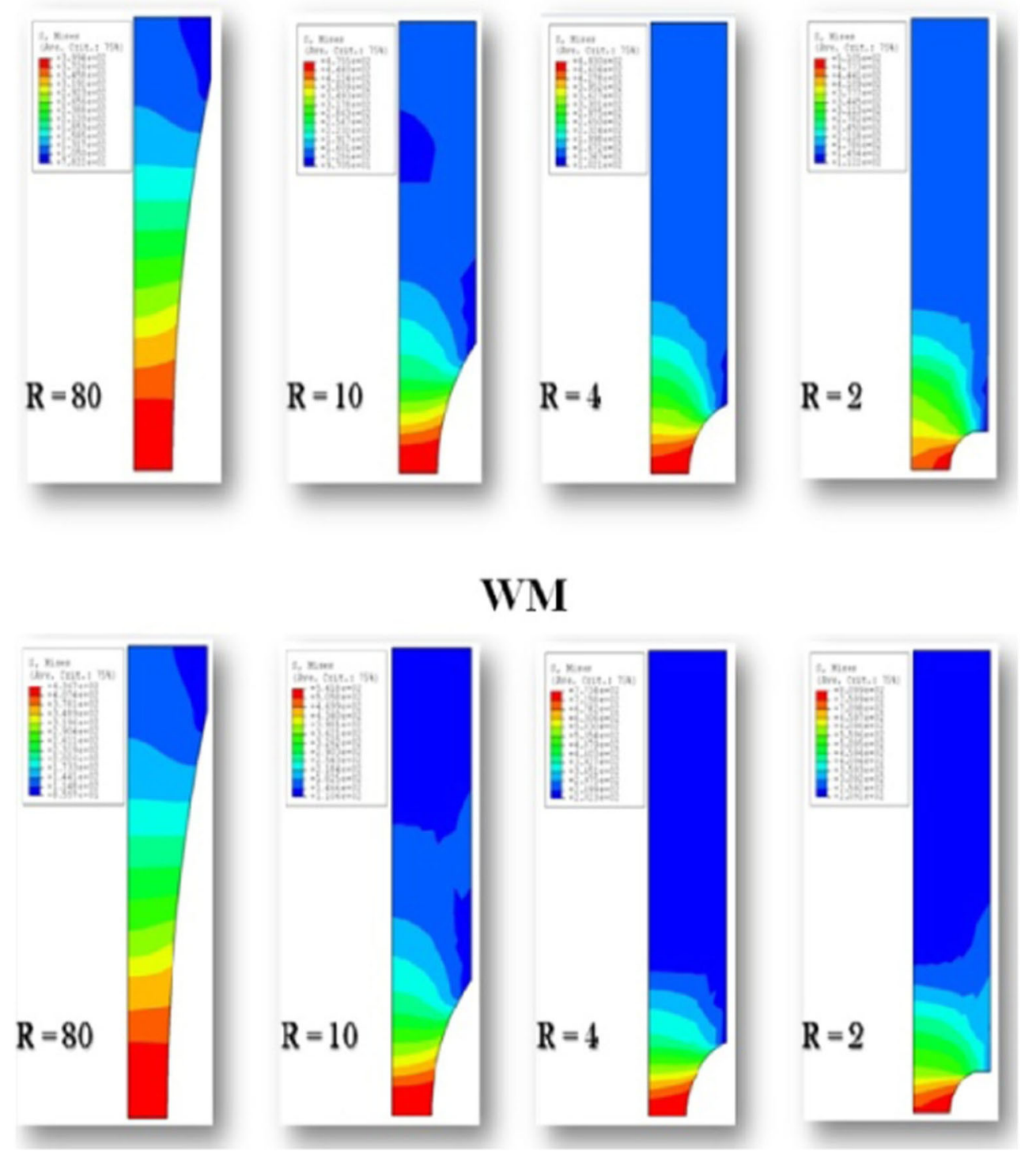

Fig. 4 Strain fields. (full colored version available online) 
Fig. 5 Evolution of the equivalent stress versus time. (full colored version available online)

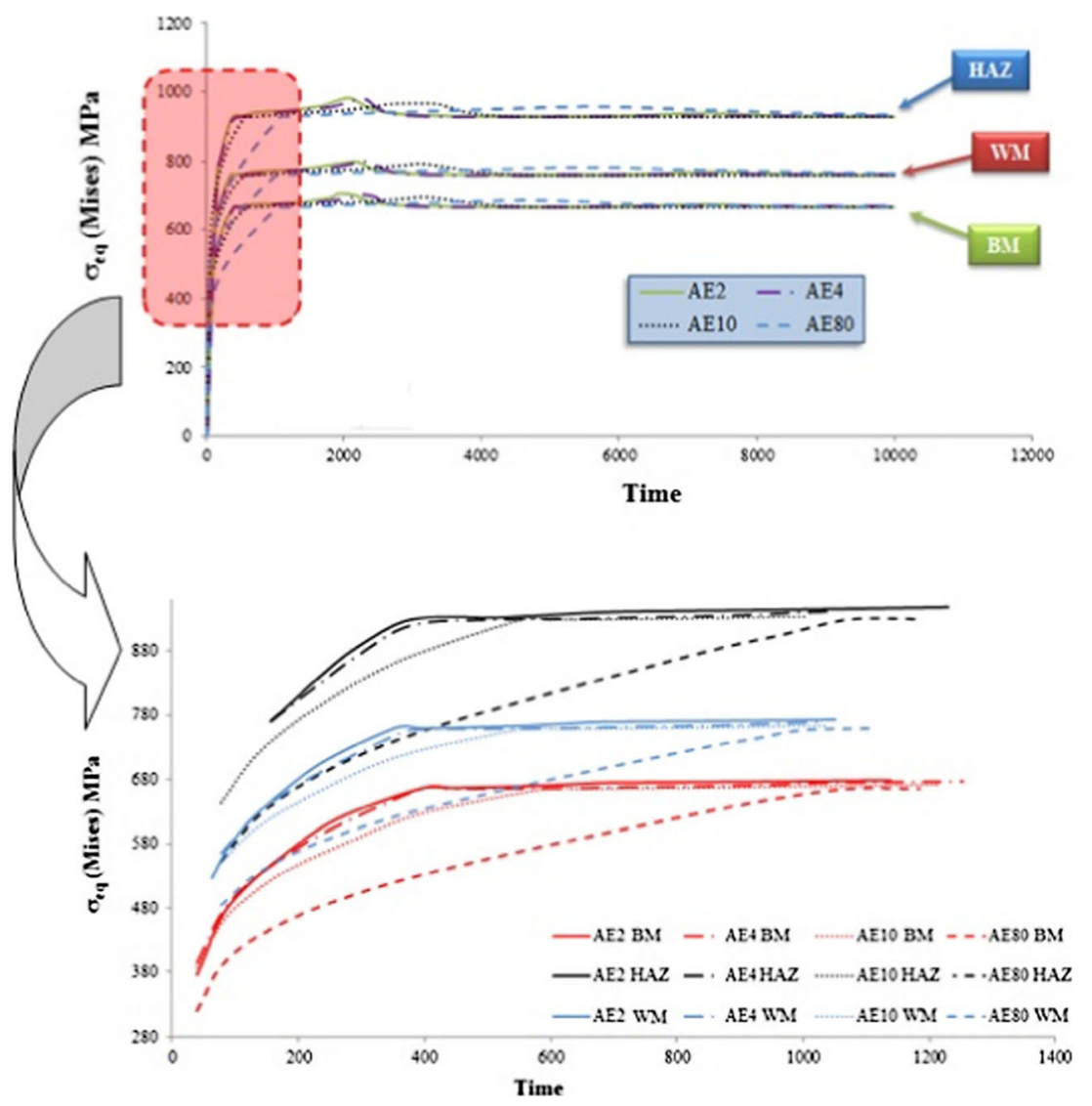

most solicited) for the same tensile tests of analysis with the four different triaxiality $\beta=0.33,0.44,0.6$, and 0.8 in different zone of weld. The results show that the equivalent stress changes when the triaxiality increases (Fig. 5).

Figure $6 a, b, c, d$ shows the variation of stress and strain in the center of the specimen as a function of time in order to study the sensitivity and the effect of triaxiality. Observed when the triaxiality increases, the maximum stress increases but the deformation remains the same. For low triaxiality, maximum stress is almost the same.

Figure 7 shows the true stress and the change in volume as a function of axial true strain, if we compare the results of true stress as a function of axial true strain for different triaxiality, we can see that all segments $\mathrm{OA}, \mathrm{AB}, \mathrm{BC}, \mathrm{CD}$, and $\mathrm{DE}$ have the same shape, which explains that $\mathrm{OA}$ is the linear part of the curve. It corresponds to the reversible deformation. AB: There is loss of linearity between load and deformation; usually $\mathrm{B}$ is considered the limit of plasticity, therefore plastic deformation beyond this limit. BC striction zone, the point $\mathrm{B}$ is associated with the beginning of the formation of a striction, which may notice a decrease in the load. The CE segment, we can say that this is the area that necking starts the CD section: a large-scale reorganization of the molecular structure of the sample. That changes shape all depends on the triaxiality given our specimens. DE is the same part of the four curves, which allows us to observe the propagation of necking which is a more or less constant load.

\section{Conclusions}

The GTN model usually used for metallic materials has been used here to model the behavior of damage welded steel. The damage in this model is described as being due to the growth of cavities, represented by parameters.

The model helped to account for all the mechanical results and determine an approach related to failure mode and fracture crazing, a criterion coalescence of cavities with rate triaxiality criterion and coalescence of cavities in the high rate of triaxiality. The maximum principal stress has been determined as the criterion for ductile-brittle transition explaining the failure modes in tension. The damage is taken into account by adjusting the parameters of the model on the evolution of volumetric strain, as well as the traction hook translating the softening of charge due to the strong growth of cavities. 
a

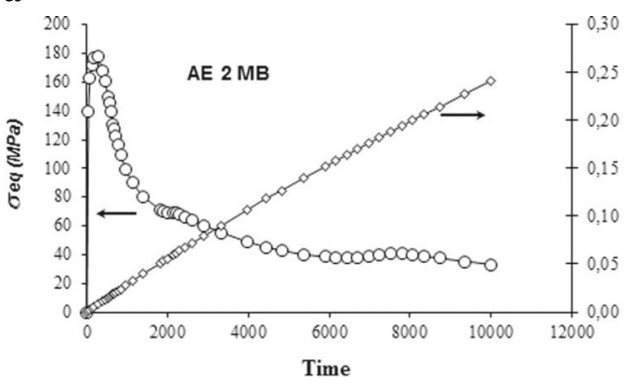

$\mathrm{c}$

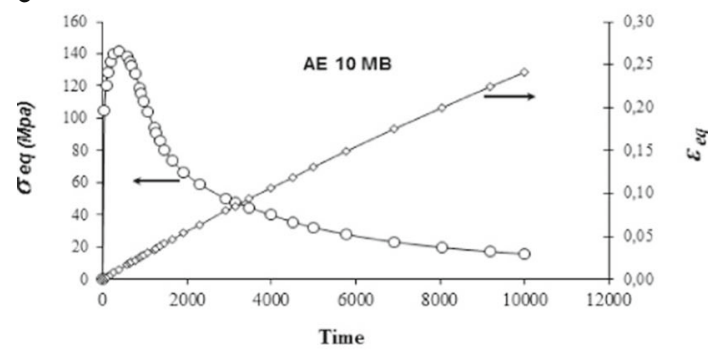

b

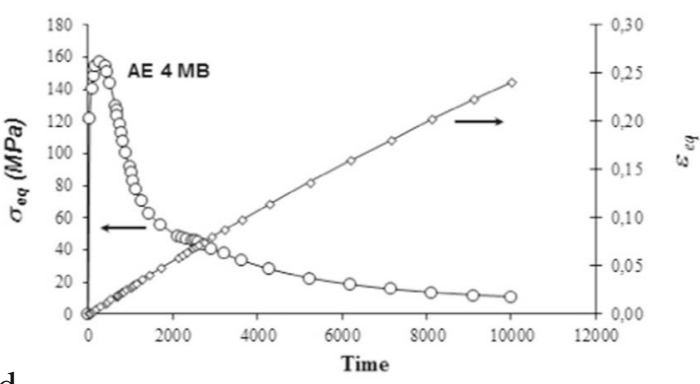

$\mathrm{d}$

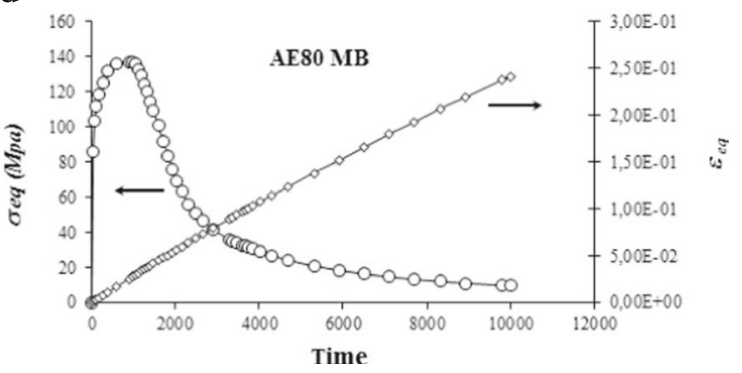

Fig. 6 a Evolution of the stress-strain versus time. $\mathbf{b}$ and $\mathbf{c}$ Evolution of the stress-strain versus time. $\mathbf{d}$ Evolution of the stress-strain versus timecontinuing

The relative error is with direction of least squares. The method of identification that we have just used is unfortunately not optimal, and the variation of a parameter is likely to involve.

In modeling, we were interested in the variation and optimization of the parameters to describe the behavior of welded steel class. The digital shutter consisting then with the exploration of the parameters was employed in our computer code. Thanks to the simplicity of the model, test them analyses gave promising results in different case. The whole of our tests of analysis in terms of local curves are acceptable even in the case of strong a

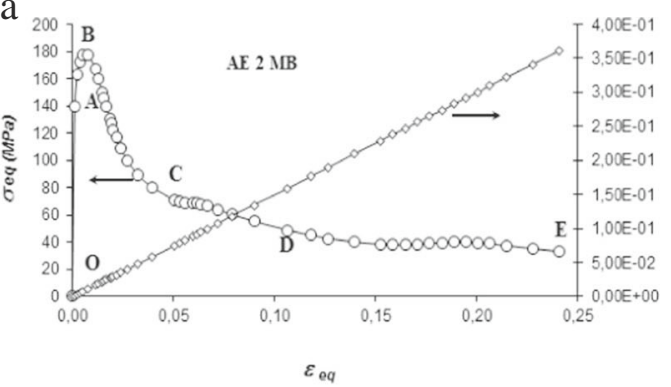

c

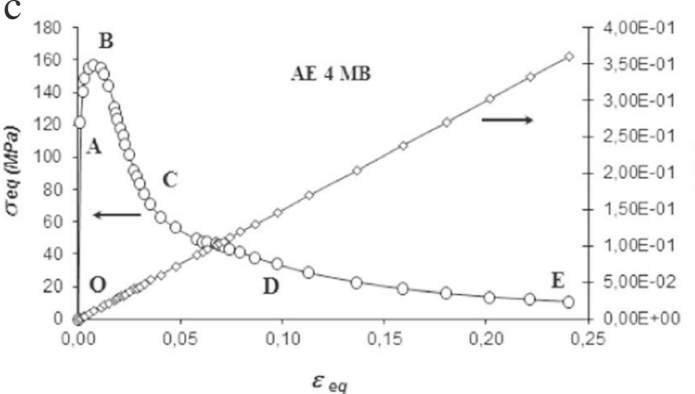

b

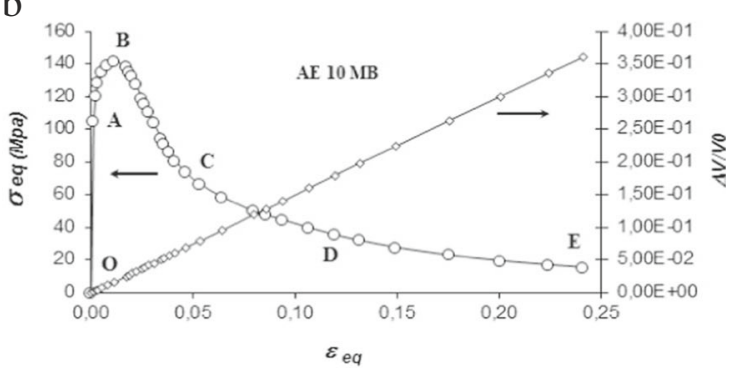

d

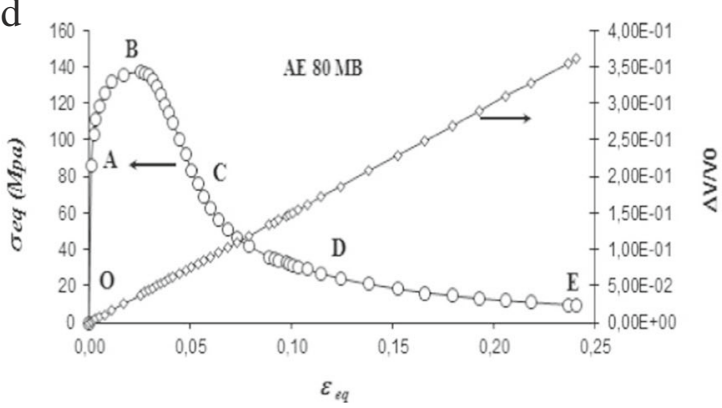

Fig. $7 \mathbf{a}$ and $\mathbf{b}$ The variation of the true stress and volume depending on the axial deformation (true). $\mathbf{c}$ and $\mathbf{d}$ The variation of the true stress and volume depending on the axial deformation (true)-continuing 
maps. Thus, the model predicts the evolution of the stress-strain in the calculation.

Open Access This article is distributed under the terms of the Creative Commons Attribution 4.0 International License (http:// creativecommons.org/licenses/by/4.0/), which permits unrestricted use, distribution, and reproduction in any medium, provided you give appropriate credit to the original author(s) and the source, provide a link to the Creative Commons license, and indicate if changes were made.

\section{References}

1. Puttick DE (1959) Philos Mag 4:964-969

2. Rogers HC (1960) Trans AIME 218:498-506

3. Brown LM, Embury JD (1973) Proc. 3rd International conference on strength of metals and alloys. Institute of metals, Cambridge, pp 164-169

4. Rice JR, Tracey DM (1969) Journal of the mechanics and physics of solids. Phys Solids 17:201-217
5. McClintock FA (1968) J Appl Mech 35:363-375

6. Hancock JW, Mackenzie AC (1976) J Mech Phys Solids 24:147-160

7. Hancock JW, Brown DK (1983) J Mech Phys Solids 31:1-24

8. Budiansky B, Hutchinson JW, Slutsky S (1982) Void growth and collapse in viscous solids. In: Hopkins HG, Sewell MJ (eds) Mechanics of solids. The Rodney Hill 60th anniversary volume, Pergamon, pp 13-45

9. Gurson AL (1977) J Eng Mater Technol 99:2-15

10. Gurson AL (1977) In: Taplin DMR (ed) Fracture 1977, international conference of fracture, 2A, pp. 357-364

11. A Needleman, JR Rice (1978) In: DP Koistinen et al. (ed) Mechanics of sheet metal forming, Plenum, pp. 237- 267

12. Tvergaard V (1982) Int J Solids Struct 18:659-672

13. Tvergaard V, Needleman A (1984) Acta Metall 32:157-169

14. Perrin G, Leblond JB (1990) Analytical study of a hollow sphere made of plastic porous material and subjected to hydrostatic tension. Int J Plast 6:677-699

15. Wisilius, Imad (2000) Fatigue \& fracture of engineering materials \& structures. 1460-2695

16. Bridgman PW (1944) Trans ASME 32:553-574

17. Nadai A (1950) Theory of flow and fracture of solids'. Mc GrawHill, New York 